\title{
The Fourth International Scientific Conference Advances in Synthesis and Complexing April 24-28, 2017
}

The 4th International Scientific Conference "Advances in Synthesis and Complexing" will be held in Moscow (April 24-28, 2017). The Conference will include the first German-Russian Interdisciplinary Student Workshop «Nanoscale Interdisciplinary Research: Physics, Chemistry, Biology, Mathematics» and the Conference for Young Scientists.

The Conference is organized by RUDN University and is dedicated to the memory of Prof. N. S. Prostakov on the 100th anniversary of his birth.

\section{Organizing Committee}
Chair
L. G. Voskressensky
A. A. Titov
V. V. Davidov
E. I. Povarova
Vice-chair
E. V. Nikitina
A. V. Varlamov
F. I. Zubkov
Yu. M. Serov
Secretary
A. A. Festa
V. N. Khrustalev
E. K. Kultishkina
V. D. Yagodovsky

\section{Sections of the Conference}

\section{Organic Chemistry}

- Modern problems of organic chemistry

- New methods in organic synthesis

- Synthesis and properties of heterocyclic compounds

- Multi-component and domino reactions
- Stereochemistry of organic compounds

- Chemistry of macrocyclic compounds

- Biologically active compounds

- Chemistry of natural products

Chair $\quad$ A. V. Varlamov, e-mail: avarlamov@sci.pfu.edu.ru, tel. +7 (495) 9550757

Secretary $\quad$ F. I. Zubkov, e-mail: fzubkov@sci.pfu.edu.ru, tel. +7 (495) 9550779

Physical and Colloidal Chemistry (the section is dedicated to the memory of Prof. V. M. Gryaznov)

- Heterogenic and homogenic catalysis

- Physico-chemical methods of investigation

- Quantum-chemical calculations

Chair Yu. M. Serov, e-mail: jserov@sci.pfu.edu.ru, tel. +7 (495) 9520745

Secretary E. I. Povarova, e-mail: eipovarova@mail.ru, tel. +7 (495) 9550844

Inorganic and Coordination Chemistry

- Complexing of metals with polyfunctional $\mathrm{N}, \mathrm{O}, \mathrm{S}$-containing ligands

- Physico-chemical investigations of inorganic and coordination compounds and new materials
- Modern problems of inorganic chemistry

- Solidphase synthesis

- X-RAY analysis

Working languages: English and Russian.

Contacts: RUDN University, Science Faculty, 3 Ordgonikidze st., Moscow, Russia. Tel/fax: +7 (495) 955 0779. E-mail: orgkom@conferencerudn.com. 